\title{
Rapid growth of an orbital hemangiopericytoma with atypical histopathological findings
}

This article was published in the following Dove Press journal:

Clinical Ophthalmology

9 December 2013

Number of times this article has been viewed

\author{
Luiz Frederico Pacheco ${ }^{1,2}$ \\ Bruno F Fernandes' \\ Cristina Miyamotol,3 \\ Shawn C Maloney' \\ Bryan Arthurs' \\ Miguel N Burnier Jr ${ }^{1,3}$ \\ 'Department of Ophthalmology, \\ McGill University Health Center, \\ Montreal, QC, Canada; ${ }^{2}$ Faculty of \\ Medicine, Federal University of Rio \\ de Janeiro, Rio De Janeiro, Brazil; \\ ${ }^{3}$ Department of Ophthalmology, \\ Federal University of São Paulo, São \\ Paulo, Brazil
}

\begin{abstract}
Hemangiopericytoma is a rare vascular tumor that originates from pericytes. The orbit is a rare location for this particular tumor, and corresponds to $0.8 \%$ to $3 \%$ of all primary orbital tumors. We report a case of a hemangiopericytoma in a 45-year-old man that had an unusual presentation, as a rapidly growing mass in the anterior right inferior orbit. Given that there are no clinical or radiological signs pathognomonic of this tumor, a careful histopathological examination is necessary to confirm the diagnosis. In our case, it presented also with unusual histopathological findings. The clinical features, radiological findings, differential diagnosis and treatment of this challenging entity are reviewed in this case report.
\end{abstract}

Keywords: hemangiopericytoma, orbit, tumor

\section{Introduction}

Hemangiopericytoma (HPC) is a rare mesenchymal tumor thought to originate from the pericytes, first identified by Zimmermann. ${ }^{1}$ Other investigators believe that HPCs arise from pluripotential perivascular cells, ${ }^{2}$ so they can occur anywhere capillaries are found. The most frequent locations are the extremities, pelvis, retroperitoneum, head, neck, and meninges. HPCs are usually deeply located within the muscle tissue, yet dermal and subcutaneous masses have also been described. HPCs are classified as benign, borderline, and malignant, depending on their clinical and histopathologic features.

Not all HPCs are typical, and some present overlapping features with other vascular and mesenchymal tumors. Immunohistochemistry helps in excluding other differential diagnoses, but some cases with unusual findings can pose a challenge to general pathologists.

\section{Case presentation}

A 45-year-old man presented with a palpable mass in the medial aspect of the right lower lid (Figure 1). The patient had noticed a rapid growth of the lesion during the previous 2 months. The clinical examination revealed a firm mass, with smooth edges, without pain, tenderness, or pulsation. Given that the mass was superficial, the surgical approach was an anterior right orbitotomy, with complete excision of the tumor mass. Macroscopic examination of the specimen revealed an oval white rubbery mass measuring $11 \times 9 \times 7 \mathrm{~mm}$. The mass was sectioned along its largest diameter and sent for processing. The interior of the lesion was solid, white, and homogeneous, without calcifications, cystic spaces, or hemorrhages. Hematoxylin and eosin sections
Correspondence: Shawn C Maloney Department of Ophthalmology, Henry C Witelson Ocular Pathology Laboratory, McGill University Health Center, Room 216, Duff Medical Building, 3775 University Street, Montreal, QC H3A-2B4, Canada

$\mathrm{Tel}+\mathrm{I} 5$ I 43987192 ext 00384

Fax +I 5143985728

Email shawn.maloney@mail.mcgill.ca 


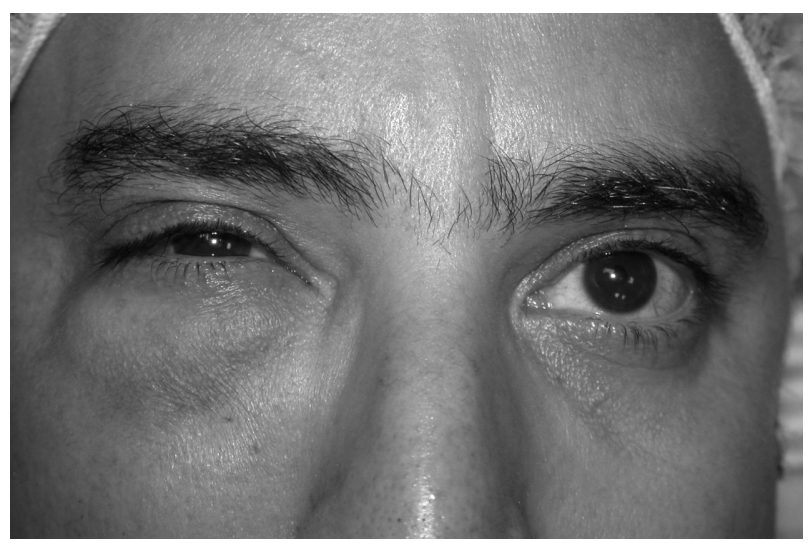

Figure I Swelling of the right lower eyelid due to the tumor in the anterior inferior orbit.

showed a tumor with a lobular pattern composed of highly cellular areas separated by dense fibrous tissue. The mass was pseudoencapsulated, and the margins were free. Under high magnification, the lobules were predominantly vascular, with the presence of small and large vessels lined by normal endothelium, in a pattern resembling the staghorn pattern typical of HPC. There were no areas of necrosis or hemorrhage. Immunohistochemistry was positive for vascular markers such as factor VIII, CD34, and Ulex (Figure 2).
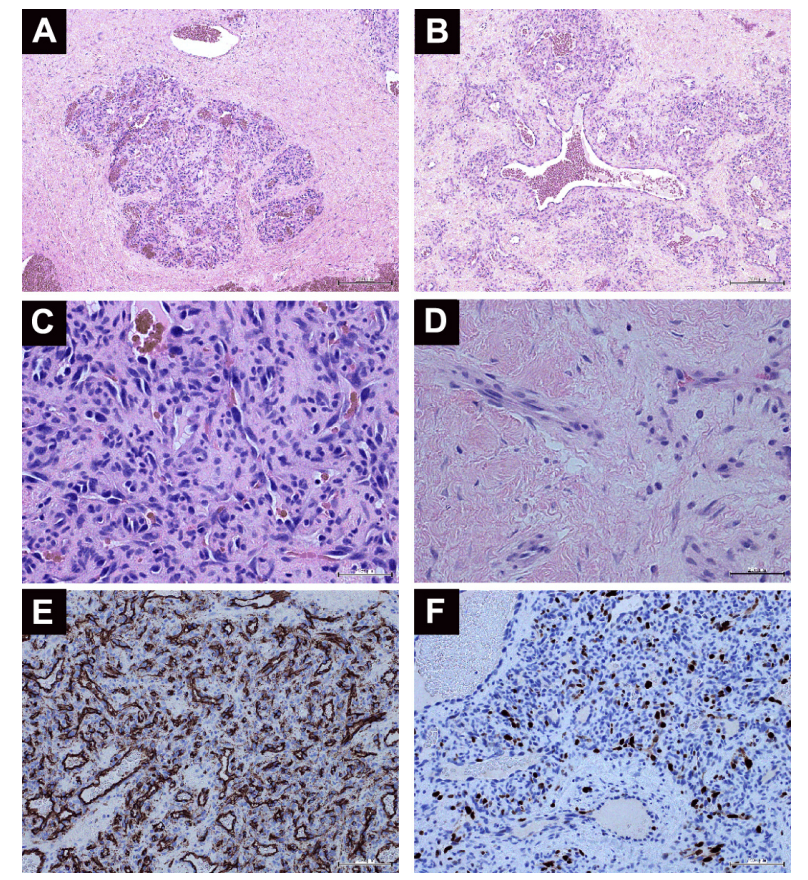

Figure 2 Histopathological analysis of an orbital hemangiopericytoma.

Notes: (A) Low-power view showing the lobular pattern of highly cellular areas separated by fibrous tissue (hematoxylin and eosin [H\&E], 40x). (B) Large, dilated vascular channels within the neoplastic cells (H\&E, 100X). (C) A high-power view of the cellular areas (H\&E, 400X). (D) The fibrotic areas separating the lobules were mostly acellular (H\&E, 400X). (E) Factor VIII-positive immunostaining (I00X). (F) Ki-67 immunostaining (200x).
D2-40, epithelial membrane antigen, S-100, and glial fibrillary acidic protein were all negative, excluding other differential diagnoses. KI-67 staining returned an average of six positive cells per field $(40 \times)$. Despite the high proliferative index, the tumor lacked other criteria to be considered malignant. The diagnosis of a benign HPC of the eyelid was then established.

\section{Discussion}

HPC is a vascular tumor of the soft tissue. It is believed that HPCs arise from pluripotential perivascular mesenchymal cells, and can occur anywhere in the body. The orbit is a rare location for this particular tumor, and corresponds to $0.8 \%$ to $3 \%$ of all primary orbital tumors. ${ }^{3}$ HPC generally affects adults (median age 45 years), with an equal sex distribution. ${ }^{46}$ It presents as a slow-growing, firm mass causing a painless proptosis, without tenderness or pulsation. Intermittent swelling and ecchymosis can also be present as the tumor grows. On computerized tomography, it generally appears as a well-circumscribed mass, which dramatically enhances after injection of contrast material. On magnetic resonance images, it is isointense in $T_{1}$, while in $T_{2}$ it can show slightly high intensity.

There are no clinical or radiological signs pathognomonic of HPC, so the diagnosis is established after careful histopathological examination. Often, the diagnosis of an HPC is made after excluding other tumors that can demonstrate HPC-like features. Grossly, it presents as a solitary, well-circumscribed, often lobulated mass with a gray to red-brown surface. Focal areas of hemorrhage can also be found. Microscopically, the lesions are composed of ovoid to spindle-shaped cells separated by sinusoidal spaces, the so-called staghorn pattern. The case described herein presented significant areas of fibrosis, which is unusual for this particular entity. The tumor also had a high proliferative index, which is in keeping with the fast growth seen clinically.

In approximately $12 \%-45 \%$ of cases, orbital HPCs metastasize. ${ }^{7}$ The most common sites of metastases are lung, mediastinum, liver, and bone. Unfortunately, the aggressive behavior of HPC is unpredictable, as it happens that apparently benign tumors eventually spread systemically. Nevertheless, some criteria have been used to classify a tumor as malignant: large diameter $(>5 \mathrm{~cm})$, increased mitotic rate (four or more figures per ten high-power fields), a high degree of cellularity, immature and pleomorphic neoplastic cells, foci of necrosis, and hemorrhage. ${ }^{8,9}$ The case described herein did not meet all criteria, and was thus considered 
benign. However, due to the unexpected and potentially aggressive behavior of the tumor, complete excision is the recommended treatment, with postoperative follow-up to detect early recurrences. A common problem is local recurrence after incomplete excision, with rates varying from $13 \%$ to $40 \%$. In cases of local recurrence, adjuvant radiotherapy and chemotherapy can be offered.

Another topic that has raised some debate is the distinction between HPC and solitary fibrous tumor (SFT). SFT was first recognized in the pleura, but soon after it was observed in other sites. Both lesions display varying features of pericytic, fibroblastic, and/or myofibroblastic differentiation, and have similar immunohistochemical profiles. To settle this controversy, a proposal to consider HPC as a cellular variant of SFT was made, although both terms are still used in the literature.

In summary, we present a rare case of orbital HPC with unusual histopathological features. We emphasize the importance of thorough histopathological examination of HPCs so that differential diagnoses, which could benefit from specific therapies, can be excluded.

\section{Disclosure}

The authors report no conflicts of interest in this work.

\section{References}

1. Zimmermann, KW. Der feinere Bau der Blutcapillaren. [The minute structure of blood capillaries.] Zeitschrift für Anatomie und Entwicklungsgeschichte. 1923;68:(1)29-109.

2. Ide F, Obara K, Mishima K, Saito I, Kusama K. Ultrastructural spectrum of solitary fibrous tumor: a unique perivascular tumor with alternative lines of differentiation. Virchows Arch. 2005;446:646-652.

3. Henderson JW, Farrow GM. Primary orbital hemangiopericytoma. An aggressive and potentially malignant neoplasm. Arch Ophthalmol. 1978;96:666-673

4. Croxatto JO, Font RL. Hemangiopericytoma of the orbit: a clinicopathologic study of 30 cases. Hum Pathol. 1982;13:210-218.

5. Tsai CC, Kau HC, Chen SJ, Hsu WM, Wu JS. Primary orbital hemangiopericytoma: a case report. Zhonghua Yi Xue Za Zhi (Taipei). 1997;59:382-385.

6. Billings KR, Fu YS, Calcaterra TC, Sercarz JA. Hemangiopericytoma of the head and neck. Am J Otolaryngol. 2000;21:238-243.

7. Panda A, Dayal Y, Singhal V, Pattnaik NK. Haemangiopericytoma. Br J Ophthalmol. 1984;68:124-127.

8. Pandey M, Kothari KC, Patel DD. Haemangiopericytoma: current status, diagnosis and management. Eur J Surg Oncol. 1997;23:282-285.

9. McMaster MJ, Soule EH, Ivins JC. Hemangiopericytoma. A clinicopathologic study and long-term followup of 60 patients. Cancer. 1975;36: $2232-2244$
Clinical Ophthalmology

\section{Publish your work in this journal}

Clinical Ophthalmology is an international, peer-reviewed journal covering all subspecialties within ophthalmology. Key topics include: Optometry; Visual science; Pharmacology and drug therapy in eye diseases; Basic Sciences; Primary and Secondary eye care; Patien Safety and Quality of Care Improvements. This journal is indexed on

Submit your manuscript here: http://www.dovepress.com/clinical-ophthalmology-journal

\section{Dovepress}

PubMed Central and CAS, and is the official journal of The Society of Clinical Ophthalmology (SCO). The manuscript management system is completely online and includes a very quick and fair peer-review system, which is all easy to use. Visit http://www.dovepress.com/ testimonials.php to read real quotes from published authors. 